\title{
Protective Effect of Loranthus globosus on Stress-Induced Major Organ Dysfunctions in Mice
}

\author{
Md. Masud Rana ${ }^{1}$, Alpana Khatun ${ }^{1}$, Md. Rafiqul Islam Khan ${ }^{1}$, Abu Syed Md Anisuzzaman ${ }^{1,2}$, \\ Mir Imam Ibne Wahed ${ }^{1, *}$ \\ ${ }^{1}$ Department of Pharmacy, Faculty of Science, University of Rajshahi, Rajshahi, Bangladesh \\ ${ }^{2}$ Department of Radiation Oncology, Winship Cancer Institute, Emory University, Atlanta, USA
}

Email address:

drmirimam a gmail.com (M. I. I. Wahed)

${ }^{*}$ Corresponding author

\section{To cite this article:}

Md. Masud Rana, Alpana Khatun, Md. Rafiqul Islam Khan, Abu Syed Md Anisuzzaman, Mir Imam Ibne Wahed. Protective Effect of Loranthus globosus on Stress-Induced Major Organ Dysfunctions in Mice. American Journal of Biomedical and Life Sciences.

Vol. 6, No. 3, 2018, pp. 43-50. doi: 10.11648/j.ajbls.20180603.12

Received: May 27, 2018; Accepted: June 22, 2018; Published: July 16, 2018

\begin{abstract}
The biochemical parameters such as SGOT, SGPT, MDA, and uric acid levels were investigated for the assessment of stress-induced dysfunction after immobilization stress on the Swiss albino mice. Stress induction caused the elevation of SGOT $(7.7 \pm 0.2 v s 88.8 \pm 0.3$; control $v s$ stress $)$, SGPT $(10.3 \pm 0.5 v s 110.5 \pm 5.2)$, MDA $(3.9 \pm 0.2 v s 9.4 \pm 0.2$ in the serum and $4.0 \pm 0.3 v s 13.9 \pm 0.2$ in brain; control $v s$ stress) and uric acid ( $7.0 \pm 0.1 v s 17.2 \pm 0.3$; control $v s$ stress) levels in the serum. Histopathology of the liver, kidney heart and lung were also examined, and morphology indicated the degradation of each of the organ by the stress induction. The bark of Loranthus globosus was extracted with methanol and then fractionated with petroleum ether (PE), chloroform (CF) and ethyl acetate (EA). Phytochemical screening confirmed the presence of flavanoids and phenolics in all fractions. The antioxidant activity was evaluated by in vitro assays using total antioxidant capacity and DPPH- free radical scavenging activity. The results demonstrated that among all the extractives of $L$. globosus EA fraction exhibited highest total antioxidant and free radical scavenging activity. The EA fraction of $L$. globosus $(12 \mathrm{mg} / \mathrm{kg}$ b. w.) successfully reduced the increased biochemical parameters (stress $v s$ stress + EAF); SGOT ( $88.8 \pm 0.3 v s 9.9$ $\pm 0.9)$, SGPT (110.5 $\pm 5.2 v s 14.6 \pm 0.7)$, MDA ( $9.5 \pm 0.2 v s 5.5 \pm 0.1$ in the serum; and $13.9 \pm 0.2 v s 7.5 \pm 0.2$ in the brain) and serum uric acid $(17.2 \pm 0.3 v s 8.9 \pm 0.1)$ on stress-induced mice. Histopathological analysis also supported the beneficial effects of EA fraction of L. globosus. Dexamethasone ( $2 \mathrm{mg} / \mathrm{kg} \mathrm{b}$. w.) was used as standard drug. The results suggested that the EA fraction of $L$. globosus might have some beneficial effects in preventing stress-induced organ dysfunction presumably through the neutralization of oxidative-stress generated during immobilization of mice. However, further study is necessary in order to precisely determine the exact molecular mechanisms.
\end{abstract}

Keywords: Loranthus globosus, Stress, SGOT and Sgpt, Antioxidant and Free Radical Scavenging

\section{Introduction}

Oxidative stress (OS) represents an imbalance between the production and manifestation of reactive oxygen species (ROS) and a biology system have the ability to readily detoxify the reactive intermediates or to repair the resulting damage. Disturbances in the normal redox state of tissue can cause toxic effects through the production of ROS, such as peroxides and free radical that damage all components of the cell. Some of the ROS (such as superoxide) can be converted by oxido-reduction reactions into more aggressive radical species that can cause excessive cellular damage [1]. By lipid peroxidation or by oxidizing DNA or proteins, the serve levels of oxidative stress cause necrosis and his damage causes ATP depletion, preventing controlled apoptotic death and causing the cell to simply fall apart [2].

Further, an excess generation of ROS in cells is known to damage DNA, lipids and proteins, resulting in a number of untoward pathophysiological effects such as mutagenesis, malignant transformation, cell death etc. [3-5]. At the initial 
stage, to eliminate deleterious ROS from the body, cells utilize various enzymatic and non-enzymatic antioxidants. However, due to excessive oxidative stress, the body's endogenous antioxidant source become exhausted which necessitates the supply of exogenous antioxidants.

In the present study, the antioxidant compound (s) in the methanolic extracts and its various fractions of Loranthus globosus and evaluated their protective effects against stressinduced major organ injury in mouse model was investigated. The analyzed serum glutamate oxaloacetate transaminase (SGOT) and serum glutamate pyruvate transaminase (SGPT) levels as biomarkers for liver and heart injury, malondialdehyde (MDA) as biomarker for lipoid peroxidation in liver and brain, and serum uric acid levels were also measured. The probable mechanisms of stressinduced oxidative damage and the protective effects of $L$. globosus were also investigated.

\section{Materials and Methods}

\subsection{Reagents}

Dexamethasone was gifted from the Kemiko Pharmaceuticals Ltd., Rajshahi, Bangladesh. 0.9\% NaCl solution (Beximco Infusion Lab., Dhaka, Bangladesh), SGOT and SGPT (AMP Medizintechnik GmbH; Austria), gallic acid standard, trichloroacetic acid, thiobarbituric acid, MDA standard and n-butanol (GE Health care, Buckinghamshire, UK) $\alpha, \alpha$-diphenyl- $\beta$-picrylhydrazyl (DPPH), sodium phosphate, ammonium molybdate, ascorbic acid and methanol (Sigma Aldrich, St. Louis, USA) were obtained from the sources noted. All employed chemicals and solvents were of analytical grade.

\subsection{Collection, Extraction and Fractionation of Plant Materials}

The barks of L. globosus were collected from Pabna, Bangladesh and were taxonomically identified by Dr. Md. Anisuzzaman, Associate Professor, Department of Botany, University of Rajshahi, Bangladesh and the voucher specimen has been preserved in the herbarium. The cleaned stem barks were dried under sunshine and subsequently in oven at $50^{\circ} \mathrm{C}$ temperatures for complete dryness.

The dried and pulverized plant material was cold extracted by methanol as described previously [13] and the methanolic extract (ME) was successively partitioned with petroleum ether (PE), chloroform (CF) and ethyl acetate (EA) using modified Kupchan partitioning method [14]. The resultant fractions were then evaporated by Rotary-dryer at low temperature $\left(40-50^{\circ} \mathrm{C}\right)$ to dryness. The fractions were preserved at $-20^{\circ} \mathrm{C}$ until further experiment. Dimethyl sulfoxide (DMSO) was used for the preparation of dose of various fractions.

\subsection{Chemical Analysis of the Methanol Extract and Its Fractions}

i) Determination of total phenolic (TP) content
The total phenolic (TP) content of the crude methanolic extract (ME) of L. globosus and its various fractions (PE, CF, EA) were determined by Folin-Ciocalteu Reagent (FCR) according to the method of Kumar et al., [6] with slight modification. Briefly, the solution of each extract $(0.5 \mathrm{ml}$, $1 \mathrm{mg} / \mathrm{ml}$ ) was diluted to $10 \mathrm{ml}$ with distilled water in a volumetric flask. FCR (1 $\mathrm{ml})$ was added and mixed thoroughly, and then sodium carbonate solution (3 $\mathrm{ml}, 2 \%)$ was added. After $2 \mathrm{~h}$ incubation at room temperature, absorbance was measured at $760 \mathrm{~nm}$. The total phenolic content was determined by comparison with the standard calibration curve of gallic acid, and results are presented as $\mathrm{mg}$ of gallic acid equivalents (mg of GAE) per gram dry weight of extracts. All tests were conducted in triplicate.

ii) Determination of total flavonoid (TF) content

The total flavonoid content of each extract was estimated by Zhishen et al. [7]. Briefly, $0.5 \mathrm{ml}(1 \mathrm{mg} / \mathrm{ml})$ of each sample was mixed with $2 \mathrm{ml}$ of distilled water and subsequently with $0.15 \mathrm{ml}$ of $\mathrm{NaNO}_{2}$ solution (15\%). After incubation for $6 \mathrm{~min}, 0.15 \mathrm{ml}$ of $\mathrm{AlCl}_{3}$ solution (10\%) was added and allowed to stand for another $6 \mathrm{~min}$. Then $2 \mathrm{ml}$ of $\mathrm{NaOH}$ solution (4\%) was added to the mixture and adjusted the final volume to $5 \mathrm{ml}$ by distilled water. The mixture was then mixed thoroughly and allowed to stand for another 15 min. The absorbance of the final solution was determined at $510 \mathrm{~nm}$. The total flavonoid content was determined by comparison with the standard calibration curve of gallic acid, and results are presented as $\mathrm{mg}$ of gallic acid equivalents ( $\mathrm{mg}$ of GAE) per gram dry weight of extracts.

\subsection{In Vitro Antioxidant Assay}

i) DPPH radical scavenging assay

The plant extracts were tested for the scavenging effect on DPPH radical according to the method of Pan et al. [8]. Accordingly, $0.2 \mathrm{ml}$ of extract solution in ethanol (95\%) at different concentrations $(1,2,4,8,16,32$ and $64 \mu \mathrm{g} / \mathrm{ml}$, respectively) was added to $8 \mathrm{ml}$ of $0.004 \%(\mathrm{w} / \mathrm{v})$ stock solution of DPPH in $95 \%$ ethanol. The scavenging activity on the DPPH radical was determined by measuring the absorbance at $517 \mathrm{~nm}$ until the reaction reached the steady state, using a UV-visible spectrophotometer (Shimadzu, Tokyo, Japan). Ascorbic acid was used as a positive control. The DPPH radical scavenging activity (S\%) was calculated using the following formula:

$$
\mathrm{S} \%=\left[\left(A_{\text {control }}-A_{\text {sample }}\right) / \mathrm{A}_{\text {control }}\right] \times 100
$$

ii) Total antioxidant activity assay

The total antioxidant activity of the methanolic extract and its various fractions of L. globosus were assessed by phosphomolybdenum method as described previously [9]. Briefly, $0.5 \mathrm{ml}$ sample solution of each fraction was mixed with $3 \mathrm{ml}$ of phosphomolybdenum solution comprising:0.6 M sulphuric acid, $28 \mathrm{mM}$ sodium phosphate and $4 \mathrm{mM}$ ammonium molybdate. The mixture was then incubated at $95^{\circ} \mathrm{C}$ for $90 \mathrm{~min}$ followed by cooling at room temperature. The absorbance of the solution was measured at $695 \mathrm{~nm}$ 
against blank. Ascorbic acid was used as a positive control.

\subsection{Induction of Immobilization Stress in Mouse Model}

Male Swiss albino mice weighing about 25-30gm were used for the development of immobilization stress model as described earlier [10]. Briefly, mice were subjected to immovable stress by keeping in a small box being one-sided small leakage and another side a stop cork so that when the mice is being entered into the box it cannot move into the box and can uptake air by the means of small aperture.

\subsection{Hepatoprotective Activity Test}

After completion of treatment with plant, drug or vehicle mice were sacrificed and approximately 2-3 $\mathrm{ml}$ of blood was collected directly from heart by syringes, centrifuged at 4000 rpm for 30 minutes to collect supernatants. Two liver enzymes most commonly used as markers of hepatic disease are serum glutamic pyruvic transaminase (SGPT) and serum glutamic oxaloacetic transaminase (SGOT). SGOT and SGPT levels were measured by UV-visible spectrophotometric method using commercial wet reagent diagnostic kits (AMP Medizintechnik GmbH; Austria) according to the manufacturer's protocol. Briefly, the amount of oxaloacetate and pyruvate formed by each of the two assays were measured by means of the 2, 4 dinitrophenylhydrazone of pyruvic acid, the color of which was read at $520 \mathrm{~nm}$ by spectrophotometer. The intensity of color was proportional to the amount of enzyme in each sample.

\subsection{Analysis of Malondialdehyde (MDA) Level}

The MDA levels from the brain tissues and serum were determined by the method of Draper and Hadley based on the reaction of MDA with thiobarbituric acid (TBA) at $95^{\circ} \mathrm{C}$ [11]. The brain tissues were homogenized separately on ice in MDA lysis buffer and centrifuged at $13,000 \times \mathrm{g}$ for $10 \mathrm{~min}$ to collect the supernatant. In the TBA test reaction, MDA and TBA react to form a pink pigment with absorption maximum at $532 \mathrm{~nm}$. The reaction was performed at $\mathrm{pH} 2-3$ at $95^{\circ} \mathrm{C}$ for $15 \mathrm{~min}$. The supernatant was mixed with 2.5 volumes of $10 \%$ $(\mathrm{w} / \mathrm{v})$ trichloroacetic acid to precipitate the protein. The precipitate was pelleted by centrifugation and supernatant was reacted with $0.67 \%$ TBA in a boiling water bath for 15 min. After cooling, the absorbance was read at $532 \mathrm{~nm}$. Arbitrary values obtained were compared with standard solutions (1, 1, 3, 3-tetramethoxypropane). Results are expressed as $\mathrm{nmol} / \mathrm{mg}$ tissue.

\subsection{Measurement of Uric Acid Level}

Uric acid was determined from uric acid kits.

Principle: Uricase

$$
\begin{gathered}
\text { Uric acid }+\mathrm{O}_{2}+\mathrm{H}_{2} \mathrm{O} \rightarrow \text { allantoine }+\mathrm{CO}_{2}+\mathrm{H}_{2} \mathrm{O}_{2} \\
2 \mathrm{H}_{2} \mathrm{O}_{2}+\text { DCHBS }+ \text { PAP } \rightarrow \text { quinoneimine } \mathrm{HCl}+4 \mathrm{H}_{2} \mathrm{O}
\end{gathered}
$$

Procedure,

$20 \mu 1$ of serum sample (or $20 \mu 1$ of standard) was mixed with $1000 \mu \mathrm{l}$ of working solution. The mixture was incubated at $37^{\circ} \mathrm{C}$ for 10 minutes. The spectrophotometer was set zero absorbance with working reagent. The absorbance for the sample and standard was taken and calculation was done as follows:

$$
\begin{gathered}
C=8 \times \frac{\text { DA of sample }}{\text { DA of standard }}(\mathrm{mg} / \mathrm{dl}) \\
C=476 \times \frac{\text { DA of sample }}{\text { DA of standard }}(\mu \mathrm{mol} / \mathrm{l})
\end{gathered}
$$

\subsection{Histopathological Study}

After seven days of observation, the animals were killed by cervical dislocation. The liver was carefully excised, rinsed in cold sucrose solution, and blotted dry with filter paper. The specimen was fixed with $10 \%$ buffered-formalin and dehydrated in ascending order of ethanol and embedded in paraffin. The blocks were sectioned with the help of rotation microtome at 6 -micron thickness. The sections were subjected to Hematoxylin and Eosin staining procedures and the histological examination was done with the aid of the high power microscope. The histological outline of each photomicrograph was conducted through a stereological grid in order to access the population of the cells in each organ. The permanent photomicrographs of each slide were recorded with a Kodak Digital Camera for subsequent histological analysis.

\subsection{Statistical Analysis}

Data were expressed as mean \pm standard error of mean (SEM). Statistical comparisons were performed by one-way analysis of variance (ANOVA), followed by Scheffe's posthoc test or students paired or unpaired t-test where appropriate. The values were considered significant when $p$ were less than $0.05(p<0.05)$. Statistical calculations and the graphs were prepared using Graph Pad Prism version 5.00 for Windows (Graph Pad Software, San Diego, CA, USA, www.graphpad.com).

\section{Results}

\subsection{Chemical Analysis of Total Phenol and Flavonoid Contents of the Crude Methanol Extract (ME) and Its Fractions of L. globosus}

The phenolic and flavonoid compounds are considered as potential antioxidants and free radical scavengers. The contents of total phenol (TP) and total flavonoid (TF) compounds in the various fractions (PE, CF and EA) of methanolic extracts of $L$. globosus were determined. The results are shown in Table 1 . The highest amount of TP and TF contents were found in EA fractions $(114.84 \pm 0.20$ and $276.90 \pm 16.34 \mathrm{GAE} \mathrm{g}^{-1}$, respectively). 
Table 1. Determination of total phenol and flavonoid contents in the crude methanol (ME) extract and its various fractions of L. globosus.

\begin{tabular}{lll}
\hline \multirow{2}{*}{ Sample } & Total phenol & Total flavonoid \\
\cline { 2 - 3 } & GAE/gm of dried extracts & GAE/gm of dried extracts \\
\hline ME extracts & $73.07 \pm 0.08$ & $198.43 \pm 5.19$ \\
PE fractions & $14.03 \pm 0.03$ & $102.50 \pm 11.3$ \\
EA fractions & $114.84 \pm 0.20$ & $276.90 \pm 16.34$ \\
CF fractions & $31.84 \pm 0.04$ & $53.21 \pm 6.09$ \\
\hline
\end{tabular}

\subsection{In Vitro Antioxidant Activity Analysis of the Crude Methanol Extract (ME) and Its Fractions of $L$. globosus}

The Figure 1A shows that there was significant scavenging of DPPH free radicals on various fractions of L. globosus. Maximum scavenging of $95.6 \pm 2.5 \%$ was observed by EA fractions in a similar extent to that of standard ascorbic acid
$(94.3 \pm 4.2 \%)$, followed by CF $(62.0 \pm 1.2 \%)$ and PEF $(61.5$ $\pm 2.4 \%$ ), respectively. Similarly, the Figure $1 \mathrm{~B}$ shows that the EA fractions have the highest total antioxidant activity. The order of total antioxidant activity in various fractions of $L$. globosus were $\mathrm{EA}>\mathrm{PE}>\mathrm{CF}$. The results are concordant with the contents of total phenolic and total flavanoid in various fractions.
$\mathbf{A}$

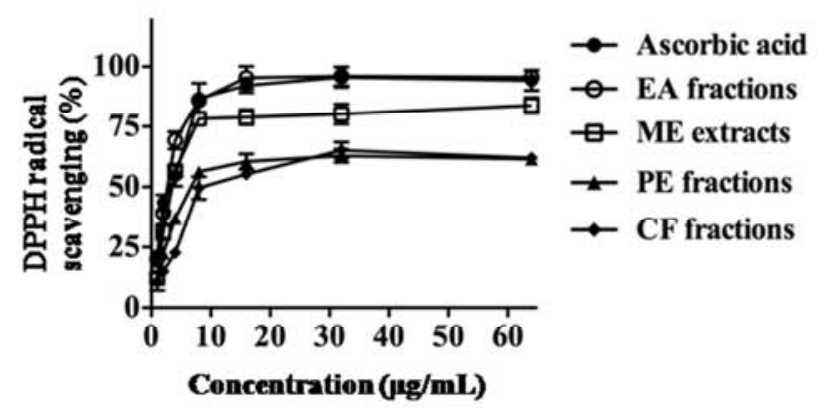

B

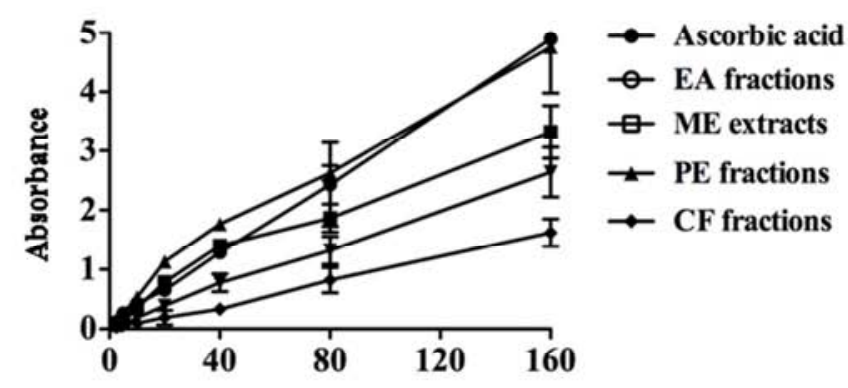

Concentration $(\mu \mathrm{g} / \mathrm{mL})$

Figure 1. (A) DPPH radical scavenging activity of crude methanol extracts (ME) and its variousfraction of L. globosus.(B) Total antioxidant activity of the crude methanol extract (ME) and its various fractions of L. globosus. Ascorbic acid was used as standard scavenger of the oxidant as well as standard antioxidant agent.

\subsection{Time Course of Stress-Induced Organ Dysfunction}

To assess the effect of stress on liver function, mice were subjected to immobilization stress for a different time period and their liver biomarkers, SGOT and SGPT were measured. As shown in Table 2, both the enzyme concentrations were gradually increasing with the increasing duration of treatment. The peak level was achieved on $7^{\text {th }}$ day treatment which was around 30-fold compared to control level.

Table 2. Time course of change in liver enzyme in stress-induced mice.

\begin{tabular}{lll}
\hline Treatment & SGPT $\left(\boldsymbol{\mu} \mathbf{k}_{\mathrm{at}} / \mathbf{l}\right)$ & SGOT $\left(\boldsymbol{\mu \mathbf { k } _ { \mathrm { at } } / \mathbf { l } )}\right.$ \\
\hline Control & $10.2 \pm 0.3$ & $7.7 \pm 0.2$ \\
Stress - 1 Day & $15.0 \pm 0.2$ & $14.2 \pm 0.3$ \\
Stress - 2 Day & $20.1 \pm 0.2^{*}$ & $18.03 \pm 0.4^{*}$ \\
Stress -3 Day & $27.2 \pm 0.3^{*}$ & $22.8 \pm 0.4^{*}$ \\
Stress - 4 Day & $32.9 \pm 0.2^{*}$ & $28.9 \pm 0.3^{*}$ \\
Stress - 5 Day & $58.2 \pm 0.2$ & $49.2 \pm 0.4^{*}$ \\
Stress -6 Day & $88.9 \pm 0.4$ & $64.9 \pm 0.3^{*}$ \\
Stress- 7 Day & $110.56 \pm 0.2$ & $88.9 \pm 0.3^{*}$ \\
Stress - 9 Day & $99.7 \pm 0.2^{*}$ & $77.8 \pm 0.3^{*}$ \\
\hline
\end{tabular}

Values are the mean \pm SEM obtained from 4-5 experiments. *: significantly different $(p<0.05)$ from the time control (tested by unpaired $t$-test).

\subsection{Dose Dependent Effect of EA Fraction of L. globosus for the Reduction of SGOT Level on Stress-Induced Mice}

EA fraction of $L$. globosus reduced the elevated SGOT levels of stress-induced mice in a dose dependent manner as shown in Figure 2. Dose used was $3-15 \mathrm{mg} / \mathrm{kg} /$ body weight. Among the doses, 3 and $6 \mathrm{mg} / \mathrm{kg} /$ body weight was unable to reduce SGOT level significantly. Hence, further experiment was performed with $12 \mathrm{mg} / \mathrm{kg} /$ body weight of EA fraction.

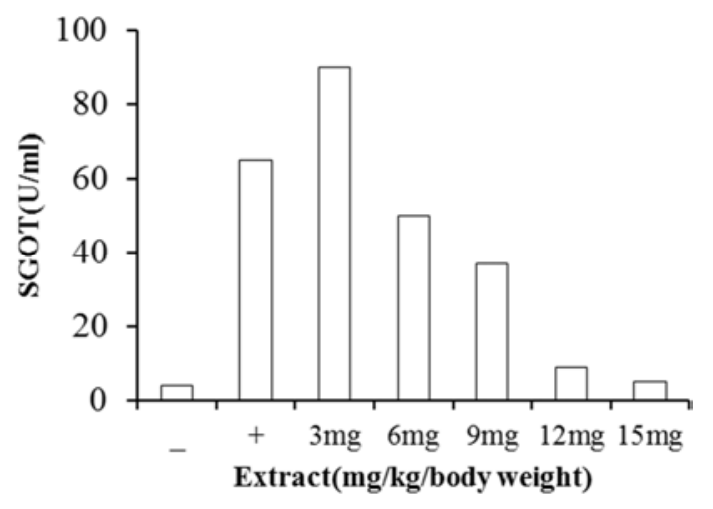

Figure 2. Dose dependent effect of EA fraction of L. globosuson SGOT level on Stress-induced mice. 


\subsection{Effect of EA Fraction of L. globosus on Various Biochemical Parameters on Stress-Induced Mice}

The effect of EA fraction of L. globosus on SGOT, SGPT, MDA and uric acid level on stress-induced mice are shown in the Table 3. Dexamethasone was used as standard antiinflammatory drug. As shown in Table 3, immobilization stress caused the significant elevation of organ biomarkers
(SGOT, SGPT, serum MDA, Uric acid), which were significantly suppressed by the administration of plant extract. Stress-induced elevated MDA levels in brain tissues were also suppressed by the treatment with EA fraction of $L$. globosus, suggesting the protective effect of EA fraction of L. globosus on stress-induced heart, liver, brain, and kidney damages.

Table 3. Effect of EAF of L. globosus on organ biomarkers in stress-induced mice.

\begin{tabular}{|c|c|c|c|c|c|}
\hline Treatment & SGPT $\left(\mu k_{a t} / l\right)$ & SGOT $\left(\mu k_{a t} / \mathbf{l}\right)$ & Serum MDA $(\mu \mathrm{M})$ & Brain MDA $(\mu \mathrm{M})$ & Serum Uric acid (mg/dL) \\
\hline Control & $10.3 \pm 0.5$ & $7.7 \pm 0.2$ & $4.7 \pm 0.2$ & $4.0 \pm 0.3$ & $9.0 \pm 0.1$ \\
\hline Stress & $110.5 \pm 5.2^{*}$ & $88.8 \pm 0.3^{*}$ & $12.5 \pm 0.2^{*}$ & $13.9 \pm 0.2 *$ & $19.9 \pm 0.3^{*}$ \\
\hline Stress + Dexa & $17.9 \pm 0.5^{\#}$ & $11.8 \pm 0.2^{\#}$ & $9.8 \pm 0.1^{\#}$ & $9.5 \pm 0.3^{\#}$ & $14.9 \pm 0.2^{\#}$ \\
\hline Stress + EAF & $14.6 \pm 0.7^{\#}$ & $9.9 \pm 0.9^{\#}$ & $7.8 \pm 0.1^{\#}$ & $7.5 \pm 0.1^{\#}$ & $11.1 \pm 0.2^{\#}$ \\
\hline
\end{tabular}

Analyses were performed by one-way ANOVA followed by Scheffe's post-hoc test. ${ }^{\star}$ : Significantly different $(\mathrm{p}<0.05)$ from time control after stress $($ tested by unpaired $t$-test). ": Significantly different $(\mathrm{p}<0.05)$ from stress control with the presence of drug as well as EA fraction of $L$. globosus. Concentration of dexamethasone and EA fraction of $L$. globosus were 2 and $12 \mathrm{mg} / \mathrm{kg}$ body weight, respectively. Values are mean $\pm \operatorname{SEM}(\mathrm{n}=4$ or 5$)$.

\subsection{Histopathological Analyzes}

Among the general changes produced by stress in mice liver, kidney, heart, and lung are shown in the Figure 3. These consist essentially of cloudy swelling, varying in intensity associated with vacuolation of protoplasm and destruction of the nuclei; ultimately destruction of cells occurred.

The liver had severe cloudy swelling on stress-induced mice and there was marked fatty degeneration. Areas of focal necrosis are found in the liver of the stress-induced mice. The interlobular connective tissue is infiltrated with small mononuclear leucocytes. Slight leukocytosis was also present in the livers. The kidneys are the seat of diffuse cloudy swelling.

Fatty degeneration is marked in the kidneys of the stressinduced mice. The connective tissue in the kidneys of the stress-induced mice was infiltrated with small mononuclear leucocytes.

\section{A Liver tissues}

i

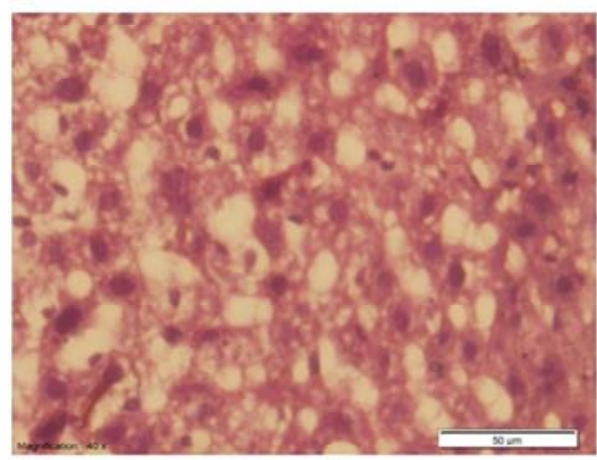

iii Control

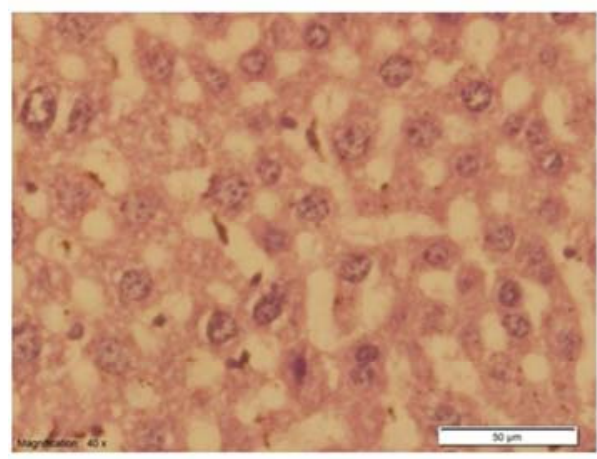

stress + Dexa ii

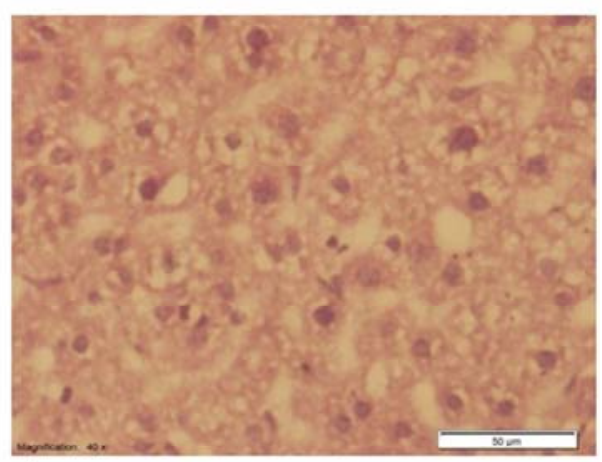

iv stress

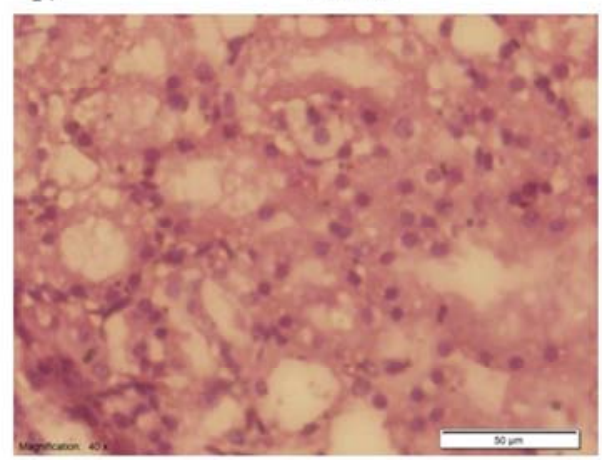

stress + EA of L. globosus 


\section{B Heart tissues}
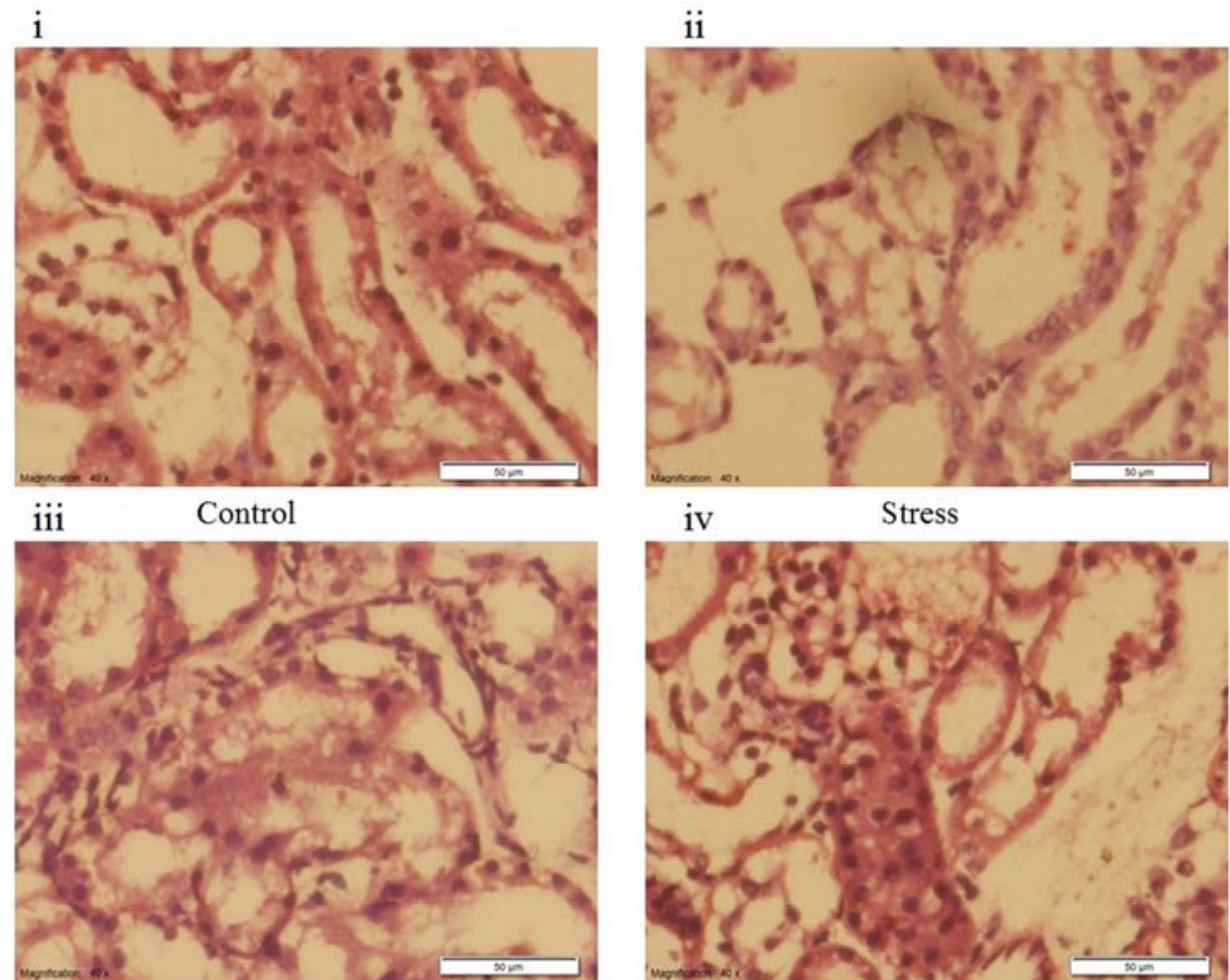

Stress + Dexa

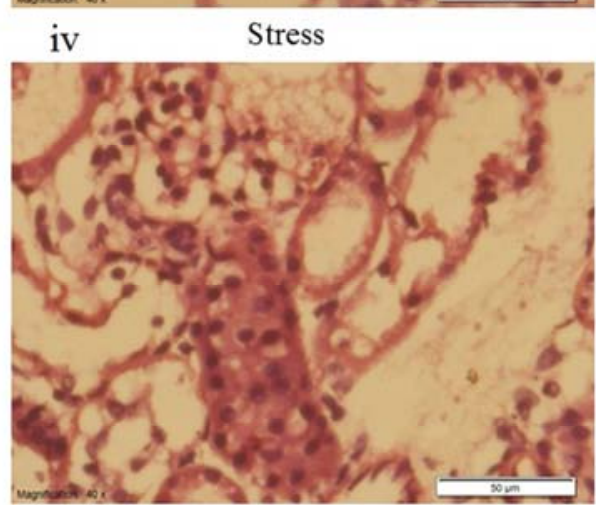

Stress + EAF of $L$. globosus

C

Kidney tissues
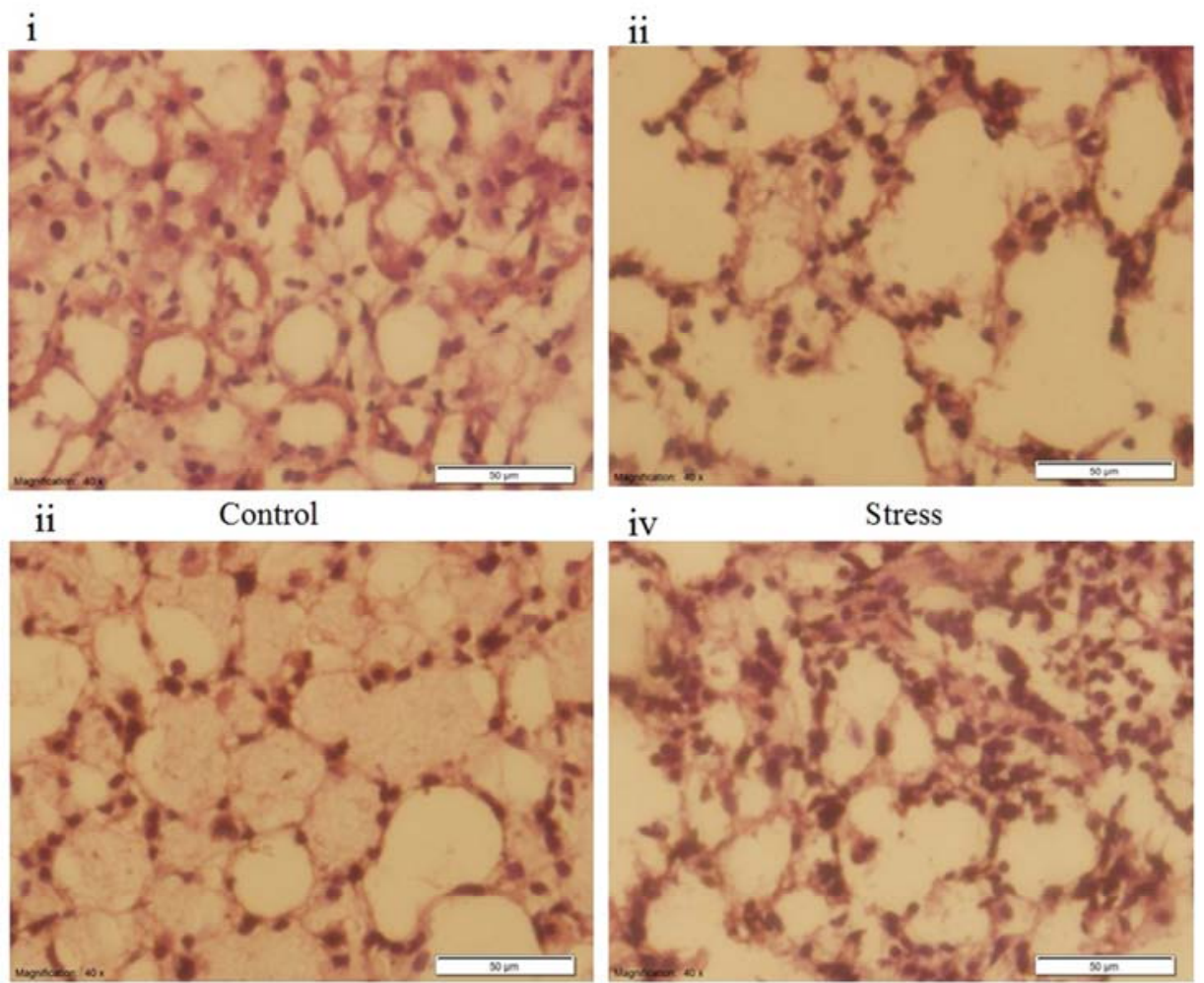

Stress + Dexa

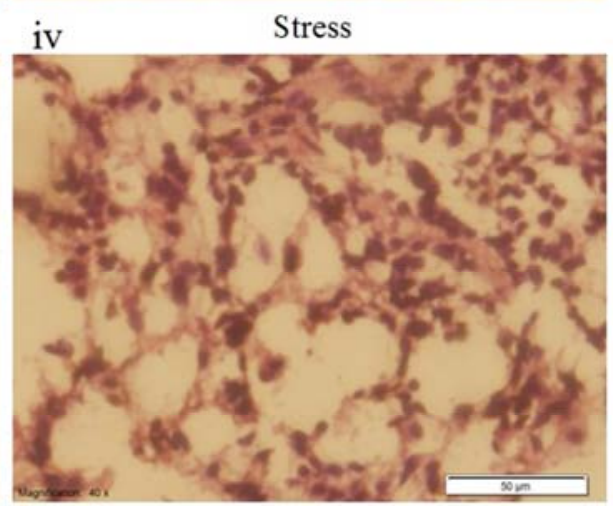

Stress + EAF L. globosus 
$\mathrm{D}$
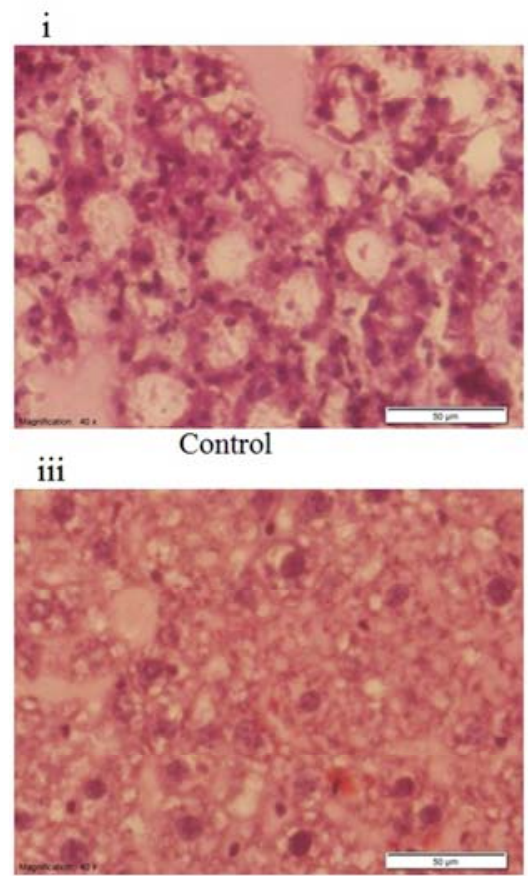

Stress + Dexa
Lung tissues
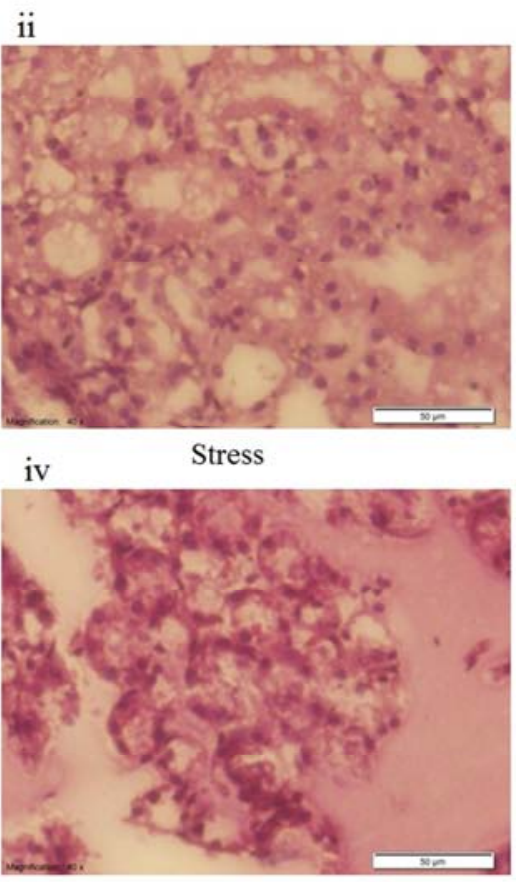

Stress + EAF L. globosus

Figure 3. Histopathological studies of stress-induced liver (A), heart (B), kidney $(C)$, and lung (D) damage with or without the treatment of EA fraction of $L$. globosus and Dexamethasone. The representative photographs shown are (i) normal control (ii) stress-induced control (iii) stress induced-induced mice treated with anti-inflammatory compound, dexamethasone and (iv) stress-induced mice treated with EA fraction of L. globosus. Scale bars, $50 \mu m$.

The lungs contained a large amount of mood and yellow pigment and eosinophlies. In some areas of the heart muscle, apparent separation of myoblasts along the intercalated discs was observed, but this was not a constant finding and probably represents tearing artifacts produced by osmication. Interestingly, the histopathological degeneration was repaired by the treatment of EA fraction of L. globosus. These lines of evidences strongly suggested the protective effects of EA fraction of L. globosus on stress-induced organ dysfunction and degeneration.

\section{Discussion}

There is a strong connection between stress and illness. Theories of the stress-illness link suggest that both acute and chronic stress can cause illness, and several studies found such a link $[12,13]$. This study has shown that regardless the method of intake, various biochemical and histological abnormalities are produced in response to stress induction. There was a prominent increase of the liver enzymes such as SGOT, and SGPT; lipid peroxidation product MDA in the serum and brain and a marker for chronic kidney disease (CKD), serum uric acid on stress-induced mice. The serum enzyme levels SGPT and SGOT are direct measure of hepatic injury and they show the status of the liver. The elevation of enzymes induced by stress causes hepatotoxicity which may be due to the generation of oxidative free radical that binds to lipoprotein and leads to peroxidation of lipids of endoplasmic reticulum. The disturbance in the transport function of the hepatocytes as a result of hepatic injury causes the leakage of enzymes from cells due to altered permeability of membrane [14]. The increased serum SGOT and SGPT level is evidence that these enzymes play an important role in the development of acute and chronic inflammation in liver [15]. The elevated level of MDA, which may be due to the free radicals, is responsible for damaging cell membranes and further intensifies inflammatory damage [16]. The inflammatory tissue damages could be due to the liberation of reactive oxygen species from phagocytes that invades the inflammatory sites [17].

Stress induction also elevated serum uric acid levels. Recent epidemiological and experimental model data suggest that uric acid may modulate CKD risk factors, specifically cardiovascular disease and metabolic syndrome. In terms of cardiovascular disease extensive epidemiological data suggests a link to uric acid [18]. These reports and our data suggested the decrease of antioxidant system both in serum and brain in stress-induced mice and overload of oxidative stress which is an important mechanism of organ damages. In our data, we have shown that stress-induced elevation of organ biomarkers was significantly suppressed by the administration of EA fraction of L. globosus (Table 3). Histological examination also suggested that EA fraction of L. globosus had the capacity to repair the stress-induced organ damages (Figure 3). Among the various phytoconstituents, flavonoids and phenolic compounds have beneficial effects in the oxidative stress-induced inflammatory condition. Flavonoids are particularly reported for significant antioxidant, vasculoprotector, antihepatotoxic, 
antiallergic, anti-inflammatory and antitumor activity [19]. Our data confirmed that EA fractions of methanolic extracts of L. globosus exhibited potential antioxidant and free radical scavenging capacity (Figure 1) due to the presence of flavonoids and phenolic compounds (Table 1). Hence, the protective effect of EA fraction could be the result of direct free radical scavenging properties [20] or by reacting with membrane phospholipid bilayers to break the chain reaction initiated by ROS [21]. Histological analyses also supported the protective effects of EA fractions of L. globosus (Figure 3 ). The improvement of the activities of antioxidant systems might be one of the results of the free radical scavenging effect of EAF of L. globosus. The detailed mechanisms are worthy of further investigation.

\section{Conclusion}

In conclusion, stress induction caused the elevation of liver biomarkers; SGOT and SGPT, lipid peroxidation biomarker, MDA in liver and brain tissues, CKD biomarker, uric acid levels, which were suppressed towards normal levels by the supplementation of the EA fractions of L. globosus presumably via the suppression of oxidative stress responsive pathways by its antioxidant and free radical scavenging activity. Although more detailed mechanisms need to be further investigated, the present work provides a potential strategy for treating major organ dysfunctions and damages.

\section{Abbreviations}

SGOT, serum glutamate oxalate transaminase; SGPT, serum glutamate pyruvate transaminase; MDA, malondialdehyde; EA, ethyl acetate; ME, methanol extract; $\mathrm{PE}$, petroleum ether; CF, chloroform; DPPH, $\alpha, \alpha$-diphenyl$\beta$-picrylhydrazyl.

\section{Conflict of Interest}

The authors declare that they have no conflict of interest.

\section{References}

[1] M. Valko, H. Morris, M. T. Cronin. Metals, toxicity and oxidative stress. Curr. Med. Chem. 12(10), (2005) 1161-208.

[2] M. D. Evans and M. S. Cooke. Factors contributing to the outcome of oxidative damage to nucleic acids. BioEssays, 26 (2004) 533-542.

[3] V. J. Thannickal, B. L. Fanburg, Reactive oxygen species in cell signaling., Am J PhysiolLung Cell Mol Physiol 279 (2000) 1005-1008.

[4] B. S. Berlett, E. R. Stadtman, Protein oxidation in aging, disease, and oxidative stress., J Biol Chem 272 (1997) 2031320316.

[5] H. Wiseman, B. Halliwell, Damage to DNA by reactive oxygen and nitrogen species: role in inflammatory disease and progression to cancer., Biochem J 313 (1996) 17-29.
[6] K. S. Kumar, K. Ganesan, P. V. S. Rao, Antioxidant potential of solvent extracts of Kappaphycus alvarezii (Doty) Doty An edible seaweed, Food Chemistry 107 (2007) 289-295.

[7] J. Zhishen, T. Mengcheng, W. Jianming, The determination of flavonoid contents in mulberry and their scavenging effects on superoxide radicals, Food Chemistry 64 (1999) 555-559.

[8] Y. Pan, K. Wang, S. Huang, H. Wang, X. Mu, C. He, X. Ji, J. Zhang, F. Huang, Antioxidant activity of microwave-assisted extract of longan (Dimocarpus Longan Lour.) peel, Food Chemistry 106 (2008) 1264-1270.

[9] P. Prieto, M. Pineda, M. Aguilar, Spectrophotometric quantitation of antioxidant capacity through the formation of a Phosphomolybdenum Complex: Specific application to the determination of vitamin E, Analytical Biochemistry 269 (1999) 337-341.

[10] A. S. M Anisuzzaman, S. Morishima, F. Suzuki, T. Tanaka, H. Yoshiki, I. Muramatsu. Identification of M1-muscarinic receptor subtype in rat stomach using a tissue segment binding method, and the effects of immobilization stress on the muscarinic receptors. Eur. J. Pharmacol. 599 (2008) 146-151.

[11] A. Khatun, M. M. Rana, M. R. I. Khan, M. I. I. Wahed, M. A. Habib, M. N. Uddin, Z. S. Sathi, A. R. M. R. Amin, A. S. M. Anisuzzaman, Molecular mechanism formalin induced toxicity and management, American J. Life Sci. 3(2015) 85-92.

[12] S. Cohen, D. J.-Deverts, W. J. Doyle, G. E. Miller, E. Frank, B. S. Rabin, and R. B. Turner. Chronic stress, glucocorticoid receptor resistance, inflammation, and disease risk. PNAS. 10 (2012) 1073.

[13] S. Cohen, D. J-Deverts, G. E. Miller. Psychological stress and diseases. JAMA. 298(10) (2007) 1685-1687.

[14] H. J. Zimmerman, L. B. Seeff, Enzymes in hepatic disease., Diagnostic Enzymology (1970).

[15] A. J. Anderson, W. E. Bocklehurst, A. L. Wills, Evidence for the role of lysosomes in the formation of prostaglandins during carrageenan induced inflammation in rat. Pharmacol. Res. Comm. 3 (1971) 13-17.

[16] R. S. Telang, S. Chatterjee, C. Varshneya, Study on analgesic and antiinflammatory avtivities of Vitex negunda Linn, Gen Pharmacol 31 (1990) 363-366.

[17] E. M. Conner, M. B. Grisham, Inflammation, free radicals, and antioxidants Nutrition 12 (1996) 274-277.

[18] D. I. Feig, D. H. Kang, R. J. Johnson. Uric acid and cardiovascular risk. N Engl J Med. 359 (2008) 1811-1821.

[19] A. M. Fernandez-Leon, M. Lozano, D. Gonzalez, M. C. Ayuso, M. F. Fernandez-Leon. Bioactive Compounds Content and Total Antioxidant Activity of Two Savoy Cabbages. Czech J. Food Sci. 32 (2014) 549-554.

[20] A. Gurel, O. Coskun, F. Armutcu, M. Kanter, O. A. Ozen, Vitamin E against oxidative damage caused by formaldehyde in frontal cortex and hippocampus: biochemical and histological studies. J Chem Neuroanat. 29 (2005) 173-178.

[21] R. J. Verma, A. Nair, Amerliorative effect of Vitamin E on aflatoxin-induced lipid peroxidation in the testis of mice. Asian J Androl. 3 (2001) 217-221. 